\title{
Theranostics of Malignant Melanoma with ${ }^{64} \mathrm{CuCl}_{2}$
}

\author{
Chunxia Qin ${ }^{1,2}$, Hongguang $\mathrm{Liu}^{1}$, Kai Chen ${ }^{1}$, Xiang Hu${ }^{1}$, Xiaowei $\mathrm{Ma}^{1}$, Xiaoli Lan ${ }^{2}$, Yongxue Zhang ${ }^{2}$, and Zhen Cheng ${ }^{1}$ \\ ${ }^{I}$ Molecular Imaging Program at Stanford (MIPS), Canary Center at Stanford for Cancer Early Detection, Department of Radiology \\ and Bio-X Program, Stanford University, Stanford, California; and ${ }^{2}$ Department of Nuclear Medicine, Union Hospital, Tongji Medical \\ College, Huazhong University of Science and Technology, Hubei Province Key Laboratory of Molecular Imaging, Wuhan, China
}

\begin{abstract}
Human copper transporter 1 (CTR1) is overexpressed in a variety of cancers. This study aimed to evaluate the use of ${ }^{64} \mathrm{CuCl}_{2}$ as a theranostic agent for PET and radionuclide therapy of malignant melanoma. Methods: CTR1 expression levels were detected by Western blot analysis of a group of tumor cell lines. Two melanoma cell lines (B16F10 and $\mathrm{A} 375 \mathrm{M})$ that highly expressed CTR1 were then selected to study the uptake and efflux of ${ }^{64} \mathrm{CuCl}_{2}$. Mice bearing $\mathrm{B} 16 \mathrm{~F} 10$ or $\mathrm{A} 375 \mathrm{M}$ tumors ( $n=4$ for each group) were subjected to 5 min of static whole-body PET scans at different time points after intravenous injection of ${ }^{64} \mathrm{CuCl}_{2}$. Dynamic scans were also obtained for B16F10 tumor-bearing mice. All mice were sacrificed at $72 \mathrm{~h}$ after injection of ${ }^{64} \mathrm{CuCl}_{2}$, and biodistribution studies were performed. Mice bearing $\mathrm{B} 16 \mathrm{~F} 10$ or $\mathrm{A} 375 \mathrm{M}$ tumors were further subjected to ${ }^{64} \mathrm{CuCl}_{2}$ radionuclide therapy. Specifically, when the tumor size reached $0.5-0.8$ $\mathrm{cm}$ in diameter, tumor-bearing mice were systemically administered ${ }^{64} \mathrm{CuCl}_{2}(\sim 74 \mathrm{MBq})$ or phosphate-buffered saline, and tumor sizes were monitored over the treatment period. Results: CTR1 was found to be overexpressed in the cancer cell lines tested at different levels, and high expression levels in melanoma cells and tissues were observed (melanotic B16F10 and amelanotic A375M). ${ }^{64} \mathrm{CuCl}_{2}$ displayed high and specific uptake in B16F10 and A375M cells. In vivo ${ }^{64} \mathrm{CuCl}_{2}$ PET imaging demonstrated that both $\mathrm{B} 16 \mathrm{~F} 10$ and A375M tumors were clearly visualized. Radionuclide treatment studies showed that the tumor growth in both the B16F10 and the A375M models under ${ }^{64} \mathrm{CuCl}_{2}$ treatment were much slower than that of the control group. Conclusion: Both melanotic and amelanotic melanomas (B16F10 and A375M) tested were found to overexpress CTR1. The tumors can be successfully visualized by ${ }^{64} \mathrm{CuCl}_{2}$ PET and further treated by ${ }^{64} \mathrm{CuCl}_{2}$, highlighting the high potential of using ${ }^{64} \mathrm{CuCl}_{2}$ as a theranostic agent for the management of melanoma.

Key Words: melanoma; copper transporter $1 ;{ }^{64} \mathrm{CuCl}_{2}$; PET; radionuclide therapy
\end{abstract}

J Nucl Med 2014; 55:812-817

DOI: 10.2967/jnumed.113.133850

$\mathbf{M}$ alignant melanoma has increased in incidence and has become a major health problem in Western countries. Beyond its strong tendency to metastasize to the lymph nodes, liver, lung, and brain, melanoma is resistant to most treatment regimens, such

Received Oct. 11, 2013; revision accepted Jan. 6, 2014.

For correspondence or reprints contact: Zhen Cheng, Molecular Imaging Program at Stanford, Canary Center at Stanford for Cancer Early Detection, Department of Radiology and Bio-X Program, 1201 Welch Rd., Lucas

Expansion, P095, Stanford University, Stanford, CA 94305.

E-mail: zcheng@stanford.edu

Published online Mar. 13, 2014.

COPYRIGHT (c) 2014 by the Society of Nuclear Medicine and Molecular Imaging, Inc. as chemotherapy and immunotherapy, making it one of the most lethal cancers $(1,2)$. Recently, the emergence of novel small molecule-based $B R A F$ inhibitors for the treatment of metastatic melanoma has shown great success in clinical studies. One of these $B R A F$ inhibitors, vemurafenib (PLX4302), can specifically target $B R A F^{V 600 E}$ and improve the overall and progression-free survival in melanoma patients. It was approved by the Food and Drug Administration for the treatment of late-stage melanoma in 2011 (3-5). However, resistance to vemurafenib treatment occurs in melanoma patients, representing a significant clinical obstacle. Strategies for preventing vemurafenib resistance, such as altered dosing (intermittent treatment), have been explored in animal models (6). However, the efficacy of this strategy remains to be tested in patients. Early, accurate diagnoses and new effective therapies are still highly desired in malignant melanoma.

Noninvasive imaging techniques play an important role in the detection of melanoma metastasis, for both accurate staging and restaging of the melanoma after treatments. Scientists have developed a variety of PET probes for melanoma imaging (1). In particular, ${ }^{18}$ F-FDG PET has demonstrated a much higher sensitivity and specificity than those obtained by CT, ultrasound, and radiography; it can detect malignant melanomas earlier than the other conventional techniques $(7,8)$. However, ${ }^{18}$ F-FDG also accumulates in many other tumor types, surgical wounds, and inflammation conditions, and thus it lacks high specificity for melanoma-specific imaging (9). Several promising and more specific imaging probes, such as melanocortin type 1 receptor (MC1R) or melanin-targeted probes, have been reported, generating great research interest (1017). Nevertheless, so far the expression level of MC1R tested in most of the human melanoma cell lines has not been high and has varied significantly, possibly limiting the use of MC1R as a biomarker for melanoma targeting (18). Similarly, melanin presents only in melanotic melanomas and can't serve as a valid target for amelanotic melanomas, which lack melanin production. To overcome the problems associated with the above probes, targeting agents against new melanoma biomarkers should be explored.

Copper is an essential micronutrient in mammals because it is a cofactor of many enzymes and is involved in biochemical processes, such as mitochondrial respiration, detoxification of free radicals, biosynthesis of neurotransmitters, formation of connective tissues and blood vessels, and reactive oxygen chemistry $(19,20)$. Human copper transporter 1 (CTR1), a 190-amino-acid protein of $28 \mathrm{kDa}$ with 3 transmembrane domains, is the primary protein responsible for importing copper in mammals (21). Interestingly, copper metabolism is also essential for many cancers; indeed, CTR1 has been found to be overexpressed in a variety of cancer cells, including non-small cell lung cancer and liver cancer $(22,23)$. The overexpression of CTR1 has also been found to be associated with 
a better cisplatin-based chemotherapy response and more favorable treatment outcomes in lung cancer patients $(24,25)$.

In this study, we first measured CTR1 expression in a group of tumor cell lines, including melanoma (B16F10, A375M, MDA-MB435 (26)), lung cancer (H460), and ovarian cancer (SKOV3), and we found that melanoma cells express a high level of CTR1. Therefore, we hypothesized that CTR1 could serve as a novel target for malignant melanoma imaging and therapy. The copper radionuclide ${ }^{64} \mathrm{Cu}$ is a cyclotron-produced radionuclide with an intermediate half-life $(12.7 \mathrm{~h})$ that decays by both $\beta+$ and $\beta-$ emission, making it suitable for theranostic (both PET imaging and radionuclide therapy) approaches to cancer treatment $(27,28)$. The substrate of CTR1, ${ }^{64} \mathrm{CuCl}_{2}$, was then evaluated as an agent for PET imaging and radionuclide therapy of malignant melanoma in both melanotic murine B16F10 and amelanotic human A375M models.

\section{MATERIALS AND METHODS}

\section{Reagents and Cell Culture}

Details of the reagents and cell culture are provided in the supplemental materials (available at http://jnm.snmjournals.org).

\section{In Vitro Studies}

First, CTR1 expression in tumor cells (H460, 22B, SKOV-3, CT26, A375M, 4T1, U87MG, HT-29, 67NR, MDA-MB-435, B16F10, and PC-3) and tissues (B16F10 and A375M) was detected by Western blot assays. Then in vitro cell uptake and efflux studies of ${ }^{64} \mathrm{CuCl}_{2}$ were performed on B16F10 and $\mathrm{A} 375 \mathrm{M}$ cells; nonradioactive $\mathrm{CuCl}_{2}$ was also used to block the uptake of ${ }^{64} \mathrm{CuCl}_{2}$ (supplemental materials).

\section{Small-Animal PET, Biodistribution Studies, and} Radionuclide Therapy Study

Animal procedures were performed according to a protocol approved by the Stanford University Institutional Animal Care and Use Committee. $\mathrm{B} 16 \mathrm{~F} 10$ and $\mathrm{A} 375 \mathrm{M}$ tumor models were prepared. Static scans were acquired at different times after injection for the mice bearing B16F10 or A375M tumors. Dynamic scans of B16F10 tumor-bearing mice were also obtained. Biodistribution studies were conducted after the 72-h PET imaging was finished.

Finally, mice bearing B16F10 or A375M tumors were subjected to ${ }^{64} \mathrm{CuCl}_{2}$ treatment. The mice were randomly divided into treatment groups and control groups (Supplemental Table 1). The weights of the mice and tumor size were measured. Hematoxylin and eosin (H\&E) staining was also performed in paraformaldehyde-fixed liver and kidney sections at the end of the study (the detailed procedure is provided in the supplemental material).

\section{Statistical Analysis}

Statistical analysis was performed using the Student $t$ test for unpaired data. A $95 \%$ confidence level was chosen to determine the significance between groups, with a $P$ value less than 0.05 being significantly different. The estimated survival distribution in the therapeutic study was calculated by the Kaplan-Meier time-to-sacrifice analysis.

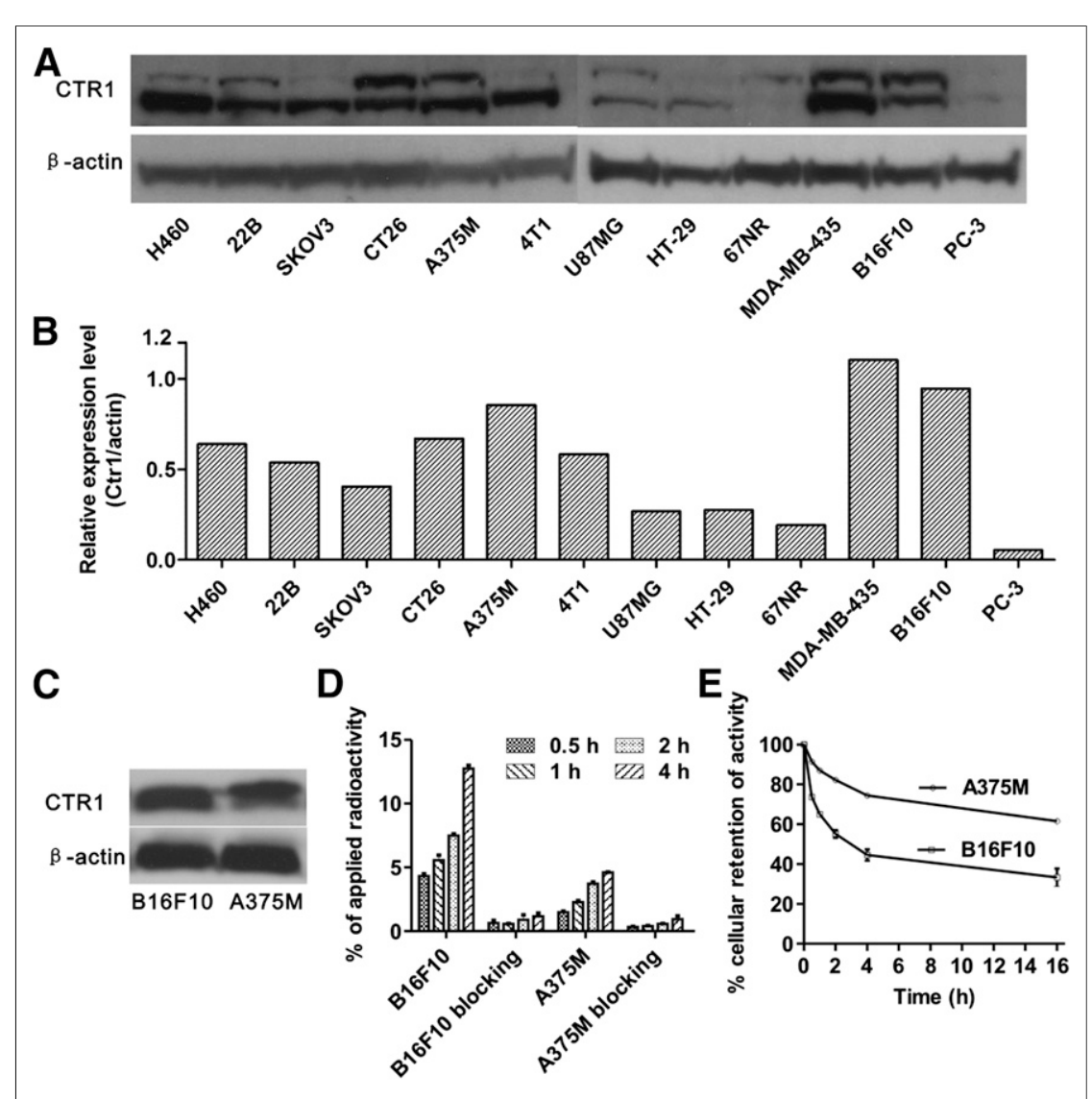

FIGURE 1. (A) Western blots of CTR1 in 12 cancer cell lines. (B) Quantitative analysis of Western blot results. (C) Western blots of CTR1 in B16F10 and A375M tumor tissues. (D) B16F10 and A375M's cellular uptake of ${ }^{64} \mathrm{CuCl}_{2}$ at $0.5,1,2$, and $4 \mathrm{~h}$ time points and blocking studies (excess cold $\mathrm{CuCl}_{2}$ was added) at each time point. (E) Efflux of ${ }^{64} \mathrm{CuCl}_{2}$ from $\mathrm{A} 375 \mathrm{M}$ and $\mathrm{B} 16 \mathrm{~F} 10$ cells at 0.5 , $1,2,4$, and $16 \mathrm{~h}$ after $2 \mathrm{~h}$ incubation with ${ }^{64} \mathrm{CuCl}_{2}$.

\section{RESULTS}

\section{Western Blot Analysis of CTR1 Expression}

The expression of CTR1 in a group of cancer cell lines measured by Western blot is shown in Figures $1 \mathrm{~A}$ and $1 \mathrm{~B}$. Interestingly, all tumor cells tested expressed a detectable level of CTR1. In particular, melanoma B16F10 and A375M cell lines were found to be among the cell lines that showed a high CTR1 expression. Moreover, high CTR1 expression in B16F10 and A375M tumor tissues was also confirmed by Western blot analysis (Fig. 1C), and the relative band intensity in B16F10 and A375M to $\beta$-actin was 0.96 and 0.89 , respectively.

\section{Cell Uptake and Efflux}

The cell uptake of ${ }^{64} \mathrm{CuCl}_{2}$ in both $\mathrm{B} 16 \mathrm{~F} 10$ and $\mathrm{A} 375 \mathrm{M}$ cells increased over time (Fig. 1D). The highest uptake of ${ }^{64} \mathrm{CuCl}_{2}$ was achieved at $4 \mathrm{~h}$, reaching $12.7 \% \pm 0.26 \%$ in the B16F10 cells and $4.6 \% \pm 0.04 \%$ in the $\mathrm{A} 375 \mathrm{M}$ cells, respectively. In the blocking groups (nonradioactive $\mathrm{CuCl}_{2}[20 \mathrm{nmol} / \mathrm{mL}]$ was used), the uptake of the probe in both $\mathrm{B} 16 \mathrm{~F} 10$ and $\mathrm{A} 375 \mathrm{M}$ cells was much lower at each time point than their corresponding nonblocking groups (Fig. 1D) $(P<0.05)$, suggesting the targeted specificity of ${ }^{64} \mathrm{CuCl}_{2}$. Next, a cellular efflux study was performed (Fig. 1E). ${ }^{64} \mathrm{CuCl}_{2}$ was slowly cleared from both cell lines, with a higher cellular retention rate in A375M than in B16F10. Specifically, 


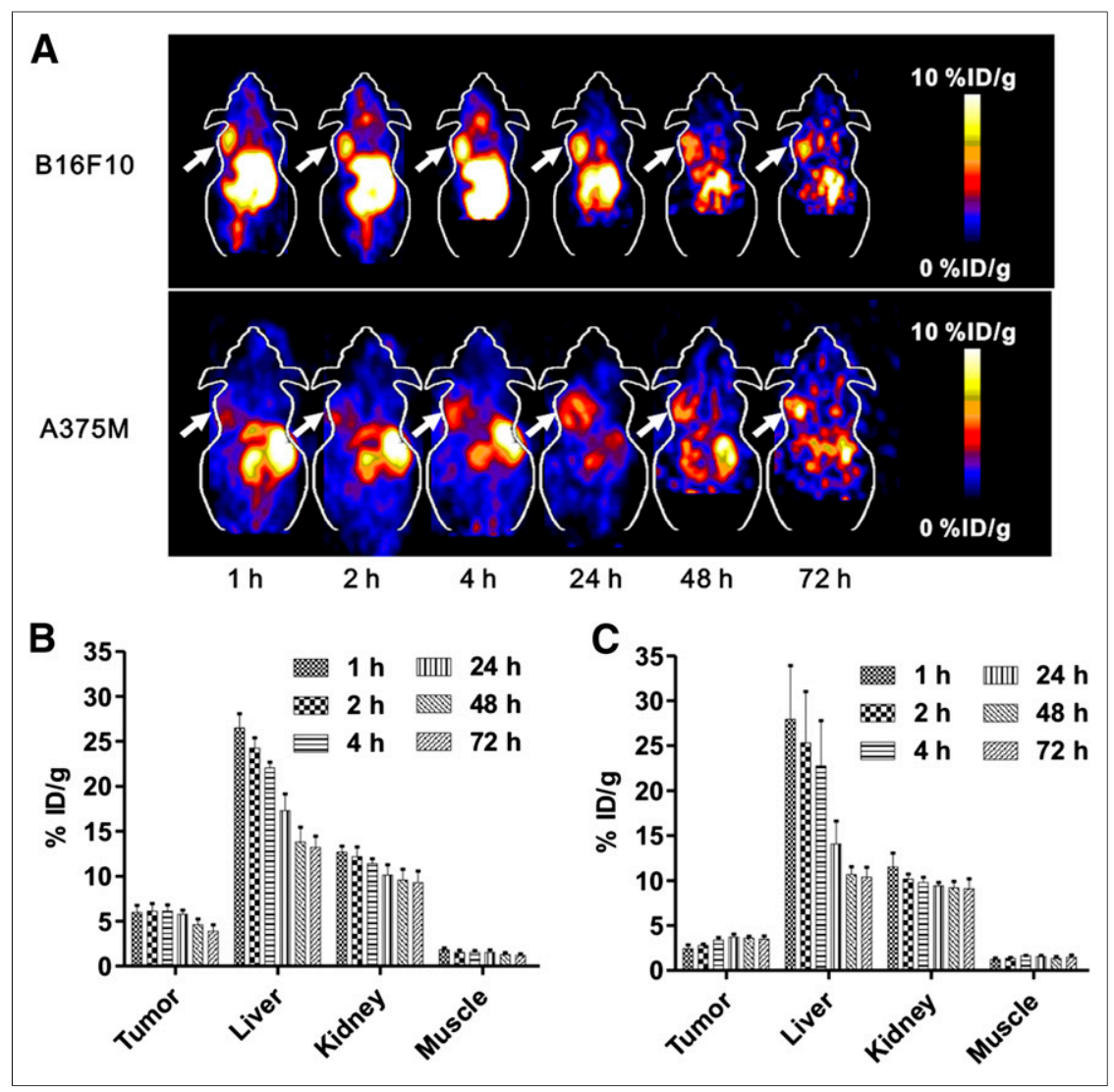

FIGURE 2. (A) Decay-corrected whole-body coronal small-animal PET images of C57BL/6 mice bearing B16F10 murine melanoma tumors (upper) and athymic nude mice bearing A375M human melanoma (lower) from 5-min static scans at 1, 2, 4, 24, 48, and $72 \mathrm{~h}$ after intravenous injection of ${ }^{64} \mathrm{CuCl}_{2}$. Tumors are indicated by arrows. (B and C) Small-animal PET quantification of tumors and major organs, including liver, kidney, and muscle, at 1, 2, 4, 24, 48, and $72 \mathrm{~h}$ after intravenous injection of ${ }^{64} \mathrm{CuCl}_{2}$ in B16F10 (B) and A375M (C) tumor-bearing mice, respectively $(n=4)$.
A 35-min dynamic small-animal PET scan for B16F10 models $(n=4)$ was also obtained to observe the uptake kinetics of ${ }^{64} \mathrm{CuCl}_{2}$ in the tumor, liver, and kidney. As shown in Figure 3, B16F10 tumor uptake gradually increased from $2.69 \pm 0.20$ $\% \mathrm{ID} / \mathrm{g}$ at $5 \mathrm{~min}$ after injection to $4.67 \pm$ $0.25 \% \mathrm{ID} / \mathrm{g}$ at the end of the $35-\mathrm{min} \mathrm{dy}-$ namic scan. Moreover, ${ }^{64} \mathrm{CuCl}_{2}$ exhibited quite high uptake in both the liver and the kidneys, rapidly accumulating in the kidneys $(21.01 \pm 2.56 \% \mathrm{ID} / \mathrm{g})$ at $5 \mathrm{~min}$ and decreasing to $14.95 \pm 1.75 \% \mathrm{ID} / \mathrm{g}$ at $35 \mathrm{~min}$ after injection. In contrast, liver uptake reached $27.37 \pm 1.94 \% \mathrm{ID} / \mathrm{g}$ at $5 \mathrm{~min}$ after injection and gradually increased to $36.49 \pm$ $2.83 \% \mathrm{ID} / \mathrm{g}$ at the end of the 35-min dynamic scan.

The biodistribution results at $72 \mathrm{~h}$ after injection confirmed the PET quantification results (Table 1). The ${ }^{64} \mathrm{CuCl}_{2}$ uptake for $\mathrm{B} 16 \mathrm{~F} 10$ and $\mathrm{A} 375 \mathrm{M}$ were $4.14 \pm 0.24$ and $3.59 \pm 0.36 \% \mathrm{ID} / \mathrm{g}$, respectively. ${ }^{64} \mathrm{CuCl}_{2}$ also showed rather high uptake in both the liver and the kidneys (>10\% ID/g). Moreover, good tumor-to-blood and tumor-tomuscle ratios were achieved for both models. For example, the tumor-to-muscle ratio of ${ }^{64} \mathrm{CuCl}_{2}$ was $4.11 \pm 0.07$ for $\mathrm{B} 16 \mathrm{~F} 10$ and $3.46 \pm 1.25$ for $\mathrm{A} 375 \mathrm{M}$, respectively.

\section{Radionuclide Therapy}

On the basis of the promising PET imaging results, the treatment efficacy of ${ }^{64} \mathrm{CuCl}_{2}$ to melanoma B16F10 and A375M were further studied. The results of the Kaplan-Meier over a $0.5 \mathrm{~h}$ incubation period, $73.6 \% \pm 0.6 \%$ of the activity presented in $\mathrm{B} 16 \mathrm{~F} 10$ cells, whereas only $33.3 \% \pm 4.4 \%$ of the activity remained over a $16 \mathrm{~h}$ period. In contrast, the activity remaining in the $\mathrm{A} 375 \mathrm{M}$ cells was $86.9 \% \pm 1.1 \%$ at $0.5 \mathrm{~h}$ and $61.6 \% \pm 0.6 \%$ at $16 \mathrm{~h}$, respectively.

\section{Small-Animal PET Scans of Tumor-Bearing Mice and Biodistribution Studies}

The representative coronal PET images of mice bearing B16F10 or A375M tumors at each time point are shown in Figure $2 \mathrm{~A}$, and the quantification analysis results of the PET images are displayed in Figures $2 \mathrm{~B}$ and $2 \mathrm{C}$. Both B16F10 and A375M tumors were clearly delineated, with excellent tumor-to-background contrast at all of the investigated time points, from 1 to $72 \mathrm{~h}$. Meanwhile, moderate-tohigh signals were observed in both the liver and the kidneys, suggesting that ${ }^{64} \mathrm{CuCl}_{2}$ was cleared from both the hepatobiliary and the renal systems (Fig. 2A). Quantification analysis further revealed that ${ }^{64} \mathrm{CuCl}_{2}$ showed similar B16F10 tumor uptake from 1 to $4 \mathrm{~h}(6.14 \pm$ 0.67 percentage injected dose per gram $[\% \mathrm{ID} / \mathrm{g}]$ at $4 \mathrm{~h}$ ), which slowly washed out and reached $3.90 \pm 0.71 \% \mathrm{ID} / \mathrm{g}$ at $72 \mathrm{~h}$ after injection. In contrast, the uptake in the A375M tumor slightly increased over time from 1 to $24 \mathrm{~h}$, with a peak value of $3.71 \pm$ $0.32 \% \mathrm{ID} / \mathrm{g}$ at $24 \mathrm{~h}$. The accumulation then remained at similar levels until $72 \mathrm{~h}$ after injection $(3.48 \pm 0.34 \% \mathrm{ID} / \mathrm{g})$. These results are consistent with those of the cellular uptake and efflux study. plot for the analysis of time-to-sacrifice for the 2 melanoma models with or without ${ }^{64} \mathrm{CuCl}_{2}$ treatment are shown in Figures $4 \mathrm{~A}-$ $4 \mathrm{C}$. The results demonstrated that the therapeutic group showed

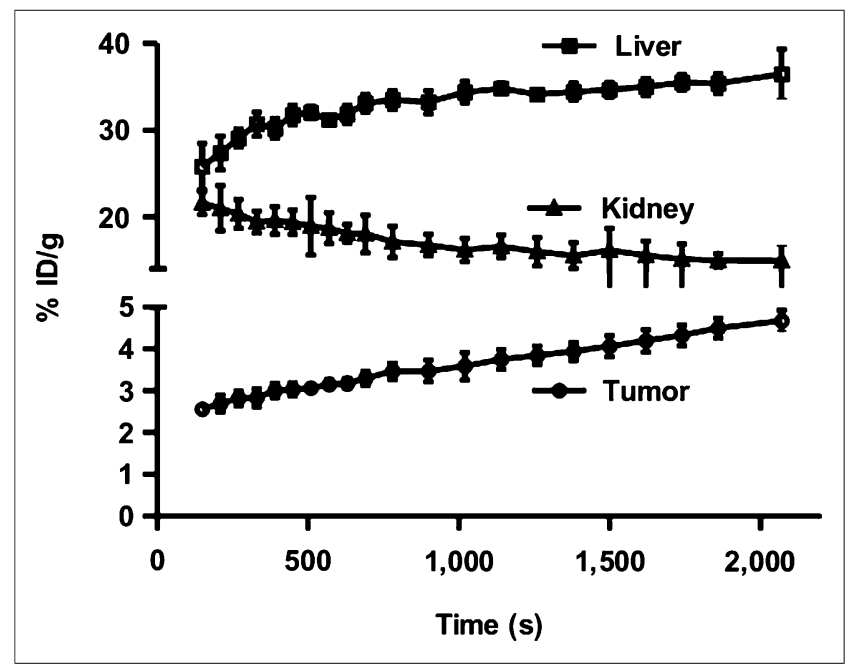

FIGURE 3. Time-activity curves of tumor and major organs of C57BL/6 mice bearing B16F10 murine melanoma tumors from 35-min dynamic scans after intravenous injection of ${ }^{64} \mathrm{CuCl}_{2}(3 \mathrm{MBq}[\sim 80 \mu \mathrm{Ci}] /$ mouse, $n=4)$. 
TABLE 1

Biodistribution Results of ${ }^{64} \mathrm{CuCl}_{2}$ in $\mathrm{B} 16 \mathrm{~F} 10$ and $\mathrm{A} 375 \mathrm{M}$ Tumor-Bearing Mice $(n=4)$

\begin{tabular}{|lrr}
\hline \multicolumn{1}{c}{ Organ } & \multicolumn{1}{c}{ B16F10 } & \multicolumn{1}{c}{ A375M } \\
\hline Blood & $1.51 \pm 0.19$ & $1.94 \pm 0.56$ \\
\hline Heart & $5.16 \pm 0.73$ & $8.85 \pm 0.65$ \\
\hline Lungs & $6.64 \pm 0.48$ & $10.17 \pm 1.58$ \\
\hline Liver & $14.06 \pm 2.33$ & $13.37 \pm 1.32$ \\
\hline Spleen & $3.46 \pm 0.42$ & $4.59 \pm 0.10$ \\
\hline Pancreas & $2.74 \pm 0.36$ & $3.48 \pm 0.61$ \\
\hline Stomach & $3.92 \pm 0.82$ & $6.47 \pm 0.86$ \\
\hline Brain & $0.88 \pm 0.09$ & $1.00 \pm 0.07$ \\
\hline Intestine & $4.35 \pm 0.99$ & $6.82 \pm 0.40$ \\
\hline Kidneys & $11.86 \pm 0.56$ & $10.34 \pm 0.53$ \\
\hline Skin & $1.18 \pm 0.51$ & $1.95 \pm 0.36$ \\
\hline Muscle & $1.03 \pm 0.18$ & $1.13 \pm 0.36$ \\
\hline Bone & $1.66 \pm 0.24$ & $1.82 \pm 0.24$ \\
\hline Tumor & $4.14 \pm 0.24$ & $3.59 \pm 0.36$ \\
\hline Uptake ratio & & \\
\hline Tumor to blood & $2.79 \pm 0.42$ & $1.94 \pm 0.44$ \\
\hline Tumor to lung & $0.63 \pm 0.07$ & $0.36 \pm 0.04$ \\
\hline Tumor to liver & $0.30 \pm 0.04$ & $0.26 \pm 0.04$ \\
\hline Tumor to muscle & $4.11 \pm 0.07$ & $3.46 \pm 1.25$ \\
\hline
\end{tabular}

Data are presented as percentage injected dose per gram $(\% \mathrm{ID} / \mathrm{g}) \pm \mathrm{SD}$.

significantly improved survival, compared with that of the control group of mice inoculated with either 1 or 2 million B16F10 cells (Figs. 4A and 4B). Moreover, the mean survival time of therapy group was $20.2 \pm 1.2$ or $12.7 \pm 0.8 \mathrm{~d}$ for the mice inoculated with 1 or 2 million cells, respectively, suggesting that the earlier treatment of tumor metastasis or relapse could achieve a better outcome. For A375M, the survival times of the therapy and control groups were $45.4 \pm 5.8$ and $20.7 \pm 2.3 \mathrm{~d}$, respectively. Kaplan-Meier survival curves revealed that the A375M mice treated with ${ }^{64} \mathrm{CuCl}_{2}$ had a significantly higher survival rate than mice treated with phosphate-buffered saline $(P<0.05)$ (Fig. 4C). Some A375M tumors of mice were found to be necrotized after ${ }^{64} \mathrm{CuCl}_{2}$ treatment (Fig. 4D).

Tumor growth curves and mouse weight variation curves for each mouse are shown in Supplemental Figures 1 and 2. For the B16F10 model, the tumors grew much faster for the group inoculated with 2 million cells (Supplemental Figures 1C and 1D) than for the 1-millioncells group (Supplemental Figures 1A and 1B). In both groups, ${ }^{64} \mathrm{CuCl}_{2}$ treatment did slightly slow down tumor growth (Supplemental Figures 1A and 1C) in comparison to the growth of the control group tumors (Supplemental Figures 1B and 1D). For A375M, the tumor growth rate was significantly slower for the treatment group than for the control group (Supplemental Figures $1 \mathrm{E}$ and $1 \mathrm{~F}$ ). In addition, ${ }^{64} \mathrm{CuCl}_{2}$ treatment showed a pronounced efficacy, compared with the treatment of B16F10 groups. Moreover, no long-term systemic toxicity was observed in the therapy groups for mice bearing B16F10 or A375M. As seen from Supplemental Figure 2, the weights of the mice in the therapy group were initially reduced but then went back to normal after several days. Further H\&E staining analysis revealed no significant difference for the liver and the kidney between the therapy group and the control group (Fig. 5). These results suggested a minimal radiotoxicity for ${ }^{64} \mathrm{CuCl}_{2}$, even though the tracer showed a relatively high uptake in those two organs.

\section{DISCUSSION}

Many new imaging and therapeutic agents for melanoma are actively being researched. Although melanin- and MC1R-targeted agents show promising properties in some melanoma small-animal models, they also suffer from their poor ability to target melanomas with low expression of either MC1R or melanin. For example, the murine melanotic B16F10 tumor shows a high expression of both MC1R and melanin, and high-quality images can be obtained by radiolabeled MC1R-targeted $\alpha$-melanocyte-stimulating hormone peptides or melanin-targeted small molecules $(10,11,14)$. On the contrary, human amelanotic A37M tumors show a low MC1R expression and lack of melanin; they also cannot be clearly imaged by MC1R- or melanin-targeted probes $(10,11,14)$, suggesting the potential limitations of those probes for clinical translation.

In this study, regardless of MC1R expression levels or colors (melanin contents), Western blot analysis showed that, of the 3 melanoma cell lines tested (B16F10, A375M, and MDA-MB-435), all had high CTR1 expression (Figs. 1A and 1B), and a variety of other tumor cell lines expressed different levels of CTR1 (from low to moderate). With the improving understanding of the role of CTR1 in tumor biology, ${ }^{64} \mathrm{CuCl}_{2}$ has been reported as a novel and promising PET probe for the imaging of Wilson disease, prostate cancer, and hepatic carcinoma (29-32), although further studies are required to verify CTR1's targeting specificity and sensitivity. We further tested the imaging quality and treatment efficacy of ${ }^{64} \mathrm{CuCl}_{2}$ for melanoma. The dynamic ${ }^{64} \mathrm{CuCl}_{2}$ PET scan of B16F10bearing mice shows that ${ }^{64} \mathrm{CuCl}_{2}$ accumulates into tumors rapidly. The successful detection of melanotic murine B16F10 and amelanotic human $\mathrm{A} 375 \mathrm{M}$ xenografts in mice by ${ }^{64} \mathrm{CuCl}_{2}$ PET (Fig. 2A) and biodistribution results indicate a high accumulation and retention of ${ }^{64} \mathrm{CuCl}_{2}$ in tumors, demonstrating the advantages of targeting melanoma through CTR1. These results also suggest that ${ }^{64} \mathrm{CuCl}_{2}$ PET may be useful for the detection of primary and

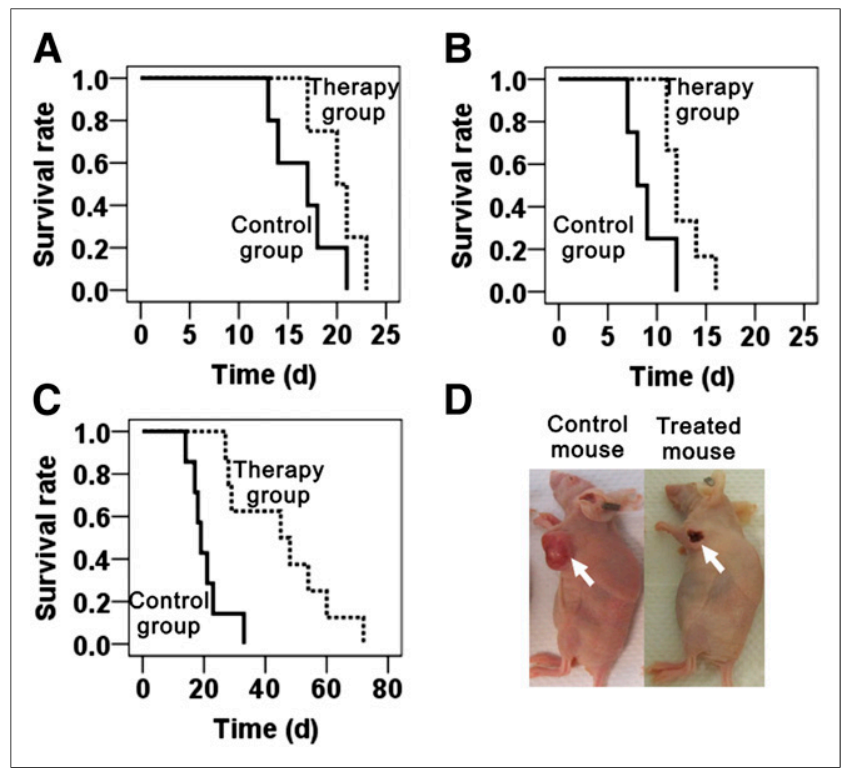

FIGURE 4. (A-C) Kaplan-Meier plot of time-to-sacrifice for therapy group (dotted line) and control group (solid line). (A) Group of mice inoculated with 1 million B16F10 cells. (B) Group of mice inoculated with 2 million B16F10 cells. (C) Group of A375M tumor models. Time is expressed in days from therapy. (D) Representative images of A375M tumor necrosis after ${ }^{64} \mathrm{CuCl}_{2}$ treatment (left, control mouse; right, treated mouse). 


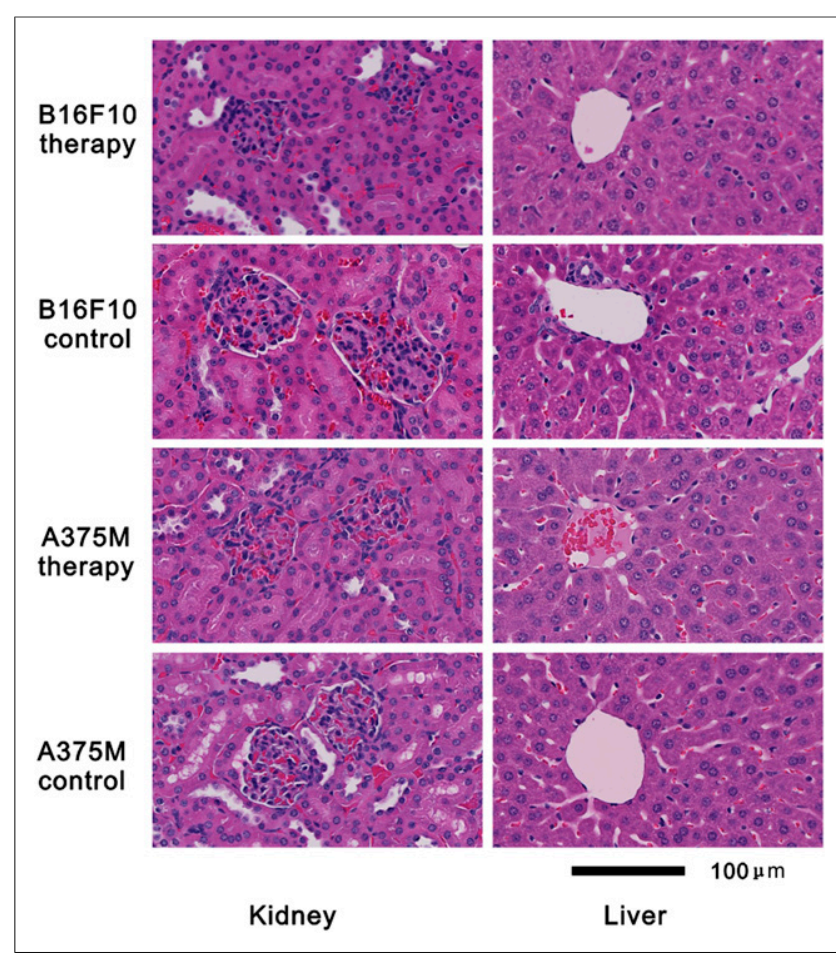

FIGURE 5. H\&E staining of livers and kidneys from therapy group and control group.

metastatic melanomas in the whole body except the abdomen because of the excretion of most ${ }^{64} \mathrm{CuCl}_{2}$ from the liver to the intestinal tract through the bile ducts (32).

Considering the decay characteristics of ${ }^{64} \mathrm{Cu}$, a treatment study was thus initiated and tested in both B16F10 and A375M models. The results clearly show that both B16F10 and A375M tumors in the therapeutic group grow more slowly than those in the control groups (Fig. 4 and Supplemental Fig. 1), suggesting that ${ }^{64} \mathrm{CuCl}_{2}$ radiotherapy is an effective and alternative therapy for those CTR1 highexpressing tumors. More interestingly, the treatment efficacy in A375M is much more pronounced than that in $\mathrm{B} 16 \mathrm{~F} 10$ (Figs. 4A-4C). Because the B16F10 tumor grows more quickly than the $\mathrm{A} 375 \mathrm{M}$ tumor, our results indicate that ${ }^{64} \mathrm{CuCl}_{2}$ may have a better therapeutic efficacy on CTR1-expressing tumors with a lower degree of malignancy.

To the best of our knowledge, this is the first report of PET imaging and therapy for both mouse melanotic B16F10 and human amelanotic A $375 \mathrm{M}$ melanomas by ${ }^{64} \mathrm{CuCl}_{2}$ that has been undertaken in conjunction with a CTR1 analysis by Western blot. This new theranostic approach for melanoma may find broad applications. These results also suggest the potential theranostic use of ${ }^{64} \mathrm{CuCl}_{2}$ for other CTR1expressing tumors, such as lung cancer, breast cancer, and glioma.

Traditionally, ${ }^{64} \mathrm{Cu}$ has been widely used to label peptides, proteins, antibodies, nanoparticles, and other biologically relevant small molecules through a variety of bifunctional chelators, such as DOTA and 1,4,8,11-tetraazacyclotetradecane- $N, N^{\prime}, N^{\prime \prime}, N^{\prime \prime \prime}$-tetraacetic acid $(10,33)$. However, these copper complexes have relatively low stability in vivo, transchelate to serum proteins $(34,35)$, or display poor acid stability, rendering the copper prone to reduction and loss from the complex (36). These circumstances result in copper accumulations in some normal organs, such as the liver, though the accumulation levels and kinetics of ${ }^{64} \mathrm{CuCl}_{2}$ and ${ }^{64} \mathrm{Cu}$-DOTA in liver are different (Supplemental Figure 3). Therefore, to minimize the circumstances caused by free radioactive copper, novel copper che- lators with high in vivo stability have recently been actively pursued (37). Compared with ${ }^{64} \mathrm{Cu}$-labeled complex, ${ }^{64} \mathrm{CuCl}_{2}$ has unique advantages, such as it is easily available and clinically translatable; has simple radiochemistry, no complex radiolabeling process involved, high stability, no issue of degradation, and high bioactivity toward CTR1; and there is a possibility for both imaging and therapy.

One of our concerns in using ${ }^{64} \mathrm{CuCl}_{2}$ as an PET imaging probe and tool for radionuclide therapy is the potential radiocytotoxicity of the high energy $\gamma$ rays and $\beta$ particles emitted by ${ }^{64} \mathrm{CuCl}_{2}(38)$. An acute response was observed for those mice treated with ${ }^{64} \mathrm{CuCl}_{2}$ (74 $\mathrm{MBq}[\sim 2 \mathrm{mCi}]$ per mouse), and weight loss was observed among the mice during the first 2-3 d after start of treatment. However, the weights of the mice recovered to normal levels after several days and retained normal growth patterns, similar to the control groups. Moreover, based on the H\&E staining results of the liver and kidney for both treated and control mice, no observable long-term radiocytotoxicity was found (Fig. 5). Lastly, PET and biodistribution results also revealed that ${ }^{64} \mathrm{CuCl}_{2}$ displayed high accumulation in the liver, intestine, and kidney, suggesting that ${ }^{64} \mathrm{CuCl}_{2}$ is mainly metabolized through hepatobiliary, gastrointestinal, and kidney systems. These results are consistent with previous findings that ${ }^{64} \mathrm{Cu}$ can bind with superoxide disumutase, which is distributed widely in the cytosol of eukaryotic cells and abundant in the liver and kidney (35). Overall, these results indicate that the therapeutic dose of ${ }^{64} \mathrm{CuCl}_{2}$ used in this study does not have any obvious systemic toxicity.

An additional concern is that there are many copper radionuclides with a varying range of half-lives and positron energies (27). For instance, ${ }^{62} \mathrm{Cu}$ is an attractive isotope because it can be easily obtained with a ${ }^{62} \mathrm{Zn} /{ }^{62} \mathrm{Cu}$ generator system, and the 9.74-min halflife of ${ }^{62} \mathrm{Cu}$ makes it suitable for perfusion study and allows repetitive imaging at reasonably brief time intervals (39). Therefore, ${ }^{62} \mathrm{CuCl}_{2}$ could also be explored to image tumors expressing CTR1 to further reduce the radiation dose in living subjects. Moreover, ${ }^{67} \mathrm{Cu}$ is another important copper radioisotope and considered as a promising radionuclide for therapy. It emits $\beta$ - particles $(0.57 \mathrm{MeV}, 100 \%)$ and $\gamma$ rays $(0.092 \mathrm{MeV}, 23 \%$; $0.184 \mathrm{MeV}, 40 \%)$ with a 2.6 -d half-life, making it suitable for both radionuclide therapy and SPECT imaging (40). It would be highly important to study the use of ${ }^{67} \mathrm{CuCl}_{2}$ for theranostics of CTR1-positive tumors in future studies.

\section{CONCLUSION}

This study is the first report, to our knowledge, to use CTR1 as a target and ${ }^{64} \mathrm{CuCl}_{2}$ as an agent for noninvasive PET imaging and radionuclide therapy of malignant melanomas. Both melanotic and amelanotic melanomas overexpressing of CTR 1 can be successfully visualized by ${ }^{64} \mathrm{CuCl}_{2}$ PET and then further treated by ${ }^{64} \mathrm{CuCl}_{2}$, highlighting the promising high clinical translational ability of ${ }^{64} \mathrm{CuCl}_{2}$ for melanoma management. Our results also suggest a potential strategy for theranostics for other CTR1-expressing tumors.

\section{DISCLOSURE}

The costs of publication of this article were defrayed in part by the payment of page charges. Therefore, and solely to indicate fact, this article is hereby marked "advertisement" in accordance with 18 USC section 1734. This work was supported, in part, by the Office of Science (BER), U.S. Department of Energy (DE-SC0008397), and NIH In vivo Cellular Molecular Imaging Center (ICMIC) grant P50 CA114747. No other potential conflict of interest relevant to this article was reported. 


\section{REFERENCES}

1. Ren G, Pan Y, Cheng Z. Molecular probes for malignant melanoma imaging. Curr Pharm Biotechnol. 2010;11:590-602.

2. Markovic SN, Erickson LA, Rao RD, et al. Malignant melanoma in the 21st century, part 1: epidemiology, risk factors, screening, prevention, and diagnosis. Mayo Clin Proc. 2007;82:364-380.

3. Tsai J, Lee JT, Wang W, et al. Discovery of a selective inhibitor of oncogenic B-Raf kinase with potent antimelanoma activity. Proc Natl Acad Sci USA. 2008;105:3041-3046.

4. Chapman PB, Hauschild A, Robert C, et al. Improved survival with vemurafenib in melanoma with BRAF V600E mutation. N Engl J Med. 2011;364:2507-2516.

5. Heakal Y, Kester M, Savage S. Vemurafenib (PLX4032): an orally available inhibitor of mutated BRAF for the treatment of metastatic melanoma. Ann Pharmacother. 2011;45:1399-1405.

6. Das Thakur M, Salangsang F, Landman AS, et al. Modelling vemurafenib resistance in melanoma reveals a strategy to forestall drug resistance. Nature. 2013;494:251-255.

7. Eigtved A, Andersson AP, Dahlstrom K, et al. Use of fluorine-18 fluorodeoxyglucose positron emission tomography in the detection of silent metastases from malignant melanoma. Eur J Nucl Med. 2000;27:70-75.

8. Schwimmer J, Essner R, Patel A, et al. A review of the literature for whole-body FDG PET in the management of patients with melanoma. Q J Nucl Med. 2000;44: 153-167.

9. Tyler DS, Onaitis M, Kherani A, et al. Positron emission tomography scanning in malignant melanoma. Cancer. 2000;89:1019-1025.

10. Cheng Z, Xiong Z, Subbarayan M, et al. ${ }^{64} \mathrm{Cu}$-labeled alpha-melanocyte-stimulating hormone analog for microPET imaging of melanocortin 1 receptor expression. Bioconjug Chem. 2007;18:765-772.

11. Cheng Z, Zhang L, Graves E, et al. Small-animal PET of melanocortin 1 receptor expression using a ${ }^{18} \mathrm{~F}$-labeled alpha-melanocyte-stimulating hormone analog. J Nucl Med. 2007;48:987-994.

12. Cheng Z, Mahmood A, Li H, et al. [99mTcOAADT]-(CH2)2-NEt2: a potential small-molecule single-photon emission computed tomography probe for imaging metastatic melanoma. Cancer Res. 2005;65:4979-4986.

13. Ren G, Liu Z, Miao Z, et al. PET of malignant melanoma using ${ }^{18} \mathrm{~F}$-labeled metallopeptides. J Nucl Med. 2009;50:1865-1872.

14. Ren G, Miao Z, Liu H, et al. Melanin-targeted preclinical PET imaging of melanoma metastasis. J Nucl Med. 2009;50:1692-1699.

15. Ren G, Liu S, Liu H, et al. Radiofluorinated rhenium cyclized alpha-MSH analogues for PET imaging of melanocortin receptor 1. Bioconjug Chem. 2010;21:2355-2360.

16. Jiang H, Kasten BB, Liu H, et al. Novel, cysteine-modified chelation strategy for the incorporation of $[\mathrm{M}(\mathrm{I})(\mathrm{CO})(3)](+)\left(\mathrm{M}=\mathrm{Re},{ }^{99 \mathrm{~m}} \mathrm{Tc}\right)$ in an alpha-MSH peptide. Bioconjug Chem. 2012;23:2300-2312.

17. Liu H, Liu S, Miao Z, et al. Development of ${ }^{18} \mathrm{~F}$-labeled picolinamide probes for PET imaging of malignant melanoma. J Med Chem. 2013;56:895-901.

18. Chen J, Cheng Z, Hoffman TJ, et al. Melanoma-targeting properties of $99 \mathrm{~m}$ technetium-labeled cyclic alpha-melanocyte-stimulating hormone peptide analogues. Cancer Res. 2000;60:5649-5658.

19. Nose Y, Wood LK, Kim BE, et al. Ctr1 is an apical copper transporter in mammalian intestinal epithelial cells in vivo that is controlled at the level of protein stability. J Biol Chem. 2010;285:32385-32392.

20. Howell SB, Safaei R, Larson CA, et al. Copper transporters and the cellular pharmacology of the platinum-containing cancer drugs. Mol Pharmacol. 2010;77:887-894.
21. Zhou B, Gitschier J. hCTR1: a human gene for copper uptake identified by complementation in yeast. Proc Natl Acad Sci USA. 1997;94:7481-7486.

22. Theophanides T, Anastassopoulou J. Copper and carcinogenesis. Crit Rev Oncol Hematol. 2002;42:57-64

23. Holzer AK, Varki NM, Le QT, et al. Expression of the human copper influx transporter 1 in normal and malignant human tissues. J Histochem Cytochem. 2006;54:1041-1049.

24. Chen HH, Yan JJ, Chen WC, et al. Predictive and prognostic value of human copper transporter 1 (hCtr1) in patients with stage III non-small-cell lung cancer receiving first-line platinum-based doublet chemotherapy. Lung Cancer. 2012;75: $228-234$.

25. Kuo MT, Fu S, Savaraj N, et al. Role of the human high-affinity copper transporter in copper homeostasis regulation and cisplatin sensitivity in cancer chemotherapy. Cancer Res. 2012;72:4616-4621.

26. Rae JM, Creighton CJ, Meck JM, et al. MDA-MB-435 cells are derived from M14 melanoma cells: a loss for breast cancer, but a boon for melanoma research. Breast Cancer Res Treat. 2007;104:13-19.

27. Anderson CJ, Ferdani R. Copper-64 radiopharmaceuticals for PET imaging of cancer: advances in preclinical and clinical research. Cancer Biother Radiopharm. 2009;24:379-393.

28. Bryan JN, Jia F, Mohsin H, et al. Monoclonal antibodies for copper-64 PET dosimetry and radioimmunotherapy. Cancer Biol Ther. 2011;11:1001-1007.

29. Wang $\mathrm{H}$, Chen $\mathrm{X}$. Visualization of copper metabolism by ${ }^{64} \mathrm{CuCl}_{2}$-PET. $\mathrm{Mol}$ Imaging Biol. 2012;14:14-16.

30. Zhang H, Cai H, Lu X, et al. Positron emission tomography of human hepatocellular carcinoma xenografts in mice using copper (II)-64 chloride as a tracer with copper (II)-64 chloride. Acad Radiol. 2011;18:1561-1568.

31. Peng F, Lu X, Janisse J, et al. PET of human prostate cancer xenografts in mice with increased uptake of 64CuCl2. J Nucl Med. 2006;47:1649-1652.

32. Peng F, Liu J, Wu JS, et al. Mouse extrahepatic hepatoma detected on microPET using copper (II)-64 chloride uptake mediated by endogenous mouse copper transporter 1. Mol Imaging Biol. 2005;7:325-329.

33. Cheng Z, De Jesus OP, Kramer DJ, et al. ${ }^{64} \mathrm{Cu}$-labeled affibody molecules for imaging of HER2 expressing tumors. Mol Imaging Biol. 2010;12:316-324.

34. Boswell CA, Sun X, Niu W, et al. Comparative in vivo stability of copper-64labeled cross-bridged and conventional tetraazamacrocyclic complexes. $\mathrm{J} \mathrm{Med}$ Chem. 2004;47:1465-1474.

35. Bass LA, Wang M, Welch MJ, et al. In vivo transchelation of copper-64 from TETAoctreotide to superoxide dismutase in rat liver. Bioconjug Chem. 2000;11:527-532.

36. Woodin $\mathrm{K}$, Heroux $\mathrm{K}$, Boswell $\mathrm{C}$, et al. Kinetic inertness and electrochemical behavior of copper(II) tetraazamacrocyclic complexes: possible implications for in vivo stability. Eur J Inorg Chem. 2005;4829-4833.

37. Prasanphanich AF, Nanda PK, Rold TL, et al. $\left[{ }^{64} \mathrm{Cu}-\mathrm{NOTA}-8-A o c-B B N(7-14)\right.$ $\mathrm{NH} 2]$ targeting vector for positron-emission tomography imaging of gastrin-releasing peptide receptor-expressing tissues. Proc Natl Acad Sci USA. 2007;104:12462-12467.

38. Blower PJ, Lewis JS, Zweit J. Copper radionuclides and radiopharmaceuticals in nuclear medicine. Nucl Med Biol. 1996;23:957-980.

39. Green MA, Mathias CJ, Welch MJ, et al. Copper-62-labeled pyruvaldehyde bis (N4-methylthiosemicarbazonato)copper(II): synthesis and evaluation as a positron emission tomography tracer for cerebral and myocardial perfusion. $\mathrm{J} \mathrm{Nucl}$ Med. 1990;31:1989-1996.

40. Connett JM, Anderson CJ, Guo LW, et al. Radioimmunotherapy with a ${ }^{64} \mathrm{Cu}-$ labeled monoclonal antibody: a comparison with ${ }^{67} \mathrm{Cu}$. Proc Natl Acad Sci USA. 1996;93:6814-6818. 